\title{
Torsion of the omentum: A rare cause of acute abdomen.
}

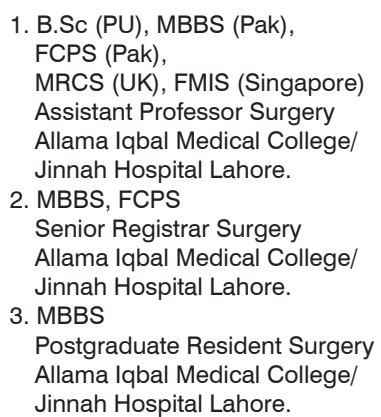

Correspondence Address:

Dr. Sajid Malik

Department of Surgery

Allama Iqbal Medical College/

Jinnah Hospital Lahore.

drsajidmalik@yahoo.com

Article received on:

30/04/2021

Accepted for publication:

08/07/2021

\begin{abstract}
Sajid Malik', Gul e Lala ${ }^{2}$, Abdullah Khan ${ }^{3}$
ABSTRACT... Omental torsion is a rare cause of acute abdominal pain. Diagnosis of omental torsion is usually difficult because clinical signs and symptoms are similar to other common causes of abdominal pain. The most common preoperative diagnosis is acute appendicitis and the proper preoperative diagnosis is important for the appropriate treatment option. Diagnosis of omental torsion is difficult and mainly based on ultrasound and computed tomography (CT) scan analysis. Case Presentation: A 26 years old male patient presented to emergency department with acute abdomen mimicking acute appendicitis. The chest and abdominal X-rays were normal. Due to intense clinical signs and worsening of the symptoms the patient underwent an operation with the probable diagnosis of acute appendicitis. In this case patient explored via gridiron incision, the omentum was found to be gangrenous that had encased the appendix so midline incision given. Post-operative recovery was uneventful. Conclusion: Omental torsion is highly uncommon cause of right lower abdominal pain and difficult to diagnose preoperatively. It presents with non-specific symptoms, mimicking other abdominal conditions presenting a similar clinical settings. CT scan is very helpful in diagnosis. Surgical treatment is the procedure of choice with laparoscopy being the preferable approach.
\end{abstract}

Key words: $\quad$ Acute Abdomen, Omental Torsion, Appendicitis, Laparotomy.

Article Citation: Malik S, Gul e Lala, Khan A. Torsion of the omentum: A rare cause of acute abdomen. Professional Med J 2021; 28(12):1869-1873. https://doi.org/10.29309/TPMJ/2021.28.12.6701

\section{INTRODUCTION}

Omental torsion is a rare cause of acute abdomen ${ }^{1}$, diagnosis of omental torsion is usually difficult because clinical signs and symptoms can mimic acute appendicitis, acute cholecystitis or even acute diverticulitis. ${ }^{2}$ Its existence is being considered by many surgeons with increasing trend due to increases frequency of detection using sophisticated investigation and diagnostic laparoscopy. ${ }^{3}$ CT scan abdomen is the investigation of choice but diagnostic laparoscopy is a gold standard. ${ }^{3}$ Treatment is the resection of the affected part of the omentum either with a laparotomy approach or laparoscopically. ${ }^{3}$

Omental torsion was first described by Eitel in 1899, around 300 cases have been reported in literature, but only few of them have been correctly diagnosed. ${ }^{4}$ It is more common in adult males of middle age group (40-50 years), and obesity being a leading risk factor. Twisting of greater
Omentum around its own axis causes vascular impairment and gangrene would be the fate for distal part. ${ }^{3,4}$ Omental torsion can be divided into two types; primary which is idiopathic, and secondary due to some predisposing risk factor where the obesity stands at top among many. ${ }^{4}$

Sudden onset of right lower abdominal pain in adult males lead surgeons to differential diagnosis of acute appendicitis or renal colicky pain, with difficulty to differentiate it specially with the acute cholecystitis as well. ${ }^{4}$ Omental torsion contributes as $0.1 \%$ of emergency exploratory laparotomies performed in patients with acute abdomen and is often ignored. Such laparotomies represent the diagnostic and definitive therapeutic procedure, laparoscopy being the procedure of choice..$^{3-4}$

\section{Case Presentation}

A 26-year-old male with BMl of $36.6 \mathrm{~kg} / \mathrm{m}^{2}$ presented in our emergency department with 
complain of abdominal pain at the right iliac fossa associated with nausea and non-bilious vomiting 4-5 episodes since morning. Patient has no history of any previous abdominal operation or signs of recent infection.

A physical examination revealed tenderness in right iliac fossa with positive rebound tenderness with positive McBurney's and Rovising's sign. Abdominal sound was audible, otherwise patient was vitally stable.

His laboratory findings showed leukocytosis with neutophilia and the rest of investigations were normal as shown in Table-I. Initial radiological investigations of chest and abdominal X-rays and ultrasound abdomen were found as normal. Surgical team on call decided to proceed for appendectomy based on clinical and radiological evidences by grid iron incision under general anesthesia.

\begin{tabular}{|l|c|c|}
\hline \multicolumn{1}{|c|}{ Labs } & Values & \multicolumn{1}{c|}{ Range } \\
\hline $\mathrm{Hb}$ & $13.2 \mathrm{~g} / \mathrm{dL}$ & 12.5 to $18.0 \mathrm{~g} / \mathrm{dL}$ \\
\hline $\mathrm{TLC}$ & $13.1 / \mathrm{mm}^{3}$ & $4000-11000$ \\
\hline PLAT & $302 \mathrm{~K} / \mathrm{uL}$ & 150 to 400 \\
\hline NET & $88 \%$ & 45 to $75 \%$ \\
\hline $\mathrm{Na}$ & $143 \mathrm{mmol} / \mathrm{L}$ & 135 to 153 \\
\hline $\mathrm{K}$ & $4.3 \mathrm{mmol} / \mathrm{L}$ & 3.5 to 5.3 \\
\hline Amylase & $76 \mathrm{U} / \mathrm{L}$ & 40 to 140 \\
\hline Creatinine & $0.7 \mathrm{mg} / \mathrm{dL}$ & 0.5 to 1.2 \\
\hline Bilirubin Total & $0.4 \mathrm{mg} / \mathrm{dL}$ & 0.3 to 1.5 \\
\hline AST & $20 \mathrm{U} / \mathrm{L}$ & Upto 40 \\
\hline ALT & $15 \mathrm{U} / \mathrm{L}$ & Upto 40 \\
\hline
\end{tabular}

Table-I. Blood investigation of patient on arrival.

On opening peritoneum, gangrenous omentum encasing the appendix was found and decision of shifting to midline laparotomy was decided and revealed whole omentum as being gangrenous. This gangrenous omentum was traced up to transverse mesocolon with torsion around its base (Figure-1).

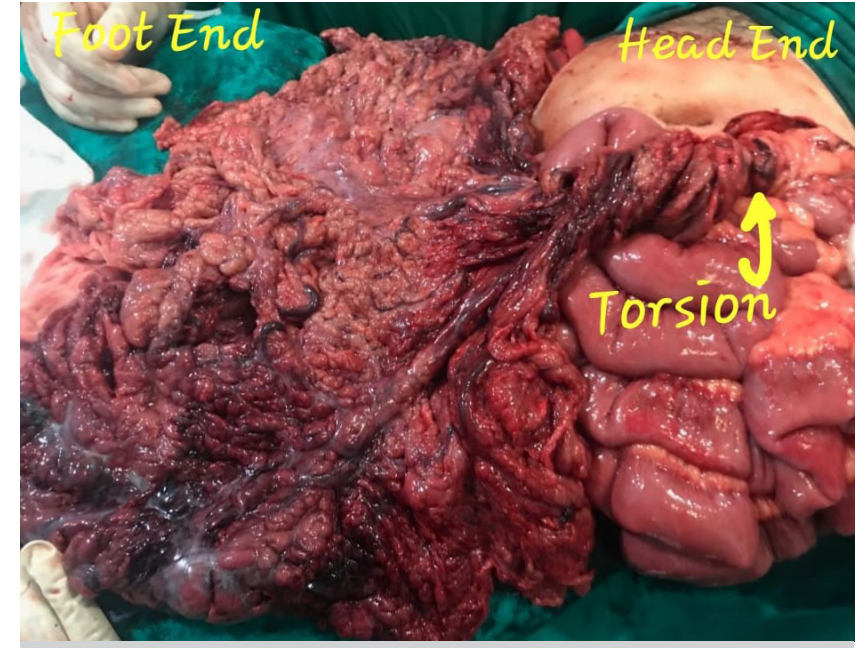

Figure-1. The affected portion of the omentum.

Detorsion of omentum done followed by omentectomy and appendectomy. Abdomen washed, drain placed and continuous closure of abdominal cavity was performed. Grid iron incision was closed back in layers. Post operatively, patient recovered well in next 24 hours with complete resolution of his symptoms in next 72 hours, and was discharged from hospital without any complications with an advice to lifestyle modification for weight management. During follow up, patient remained healthy, and reported with histopathology report on two weeks with macroscopic findings as $23 \times 14 \times$ $7 \mathrm{~cm}$ omental pedicle with cyanotic and lobed appearance. Microscopic findings confirmed extensive fat necrosis with hemorrhagic infarction with focal necrosis and polymorph neutrophil infiltration. Patient was discharged from follow up after six months and achieved a BMI of $27 \mathrm{~kg} / \mathrm{m}^{2}$.

\section{DISCUSSION}

Omental torsion is an extremely rare condition with scarce data in literature review. It was first described by Eitel in 1899, followed with almost three hundred cases so far with only a few have been diagnosed pre operatively. ${ }^{4-6}$ The most of cases were identified as an incidental per operative finding. This condition can mimic other surgical conditions like acute appendicitis therefore accurate preoperative diagnosis was reported only in 0.6-4.8\% patients. ${ }^{6}$ Omental torsion consists of $1.1 \%$ of all cases of abdominal 
pain and its incidence ranges between $0.0016 \%$ and $0.37 \%$, which is a ratio of less than 4 cases per 1000 cases of acute appendicitis. ${ }^{6-8}$

Omental torsion can present in two ways; primary and secondary. In primary torsion, which constitutes almost one third of the cases $^{4}$ spontaneous torsion and is idiopathic. Risk factors documents for are anatomical malformations like bifid or accessory omentum, sudden body movements, vigorous exercise, and hyperperistalsis have been documented as precipitating factors. Obesity is also a welldocumented risk linked to primary torsion, with one study documenting that almost $70 \%$ of patients were obese. Secondary torsion is more common and is associated with pre-existeing abdominal pathologies like inguinal hernias with omentocele (most common), omental cyst, tumor or adhesion with the dependent omentum becoming fixed in the torsed position and unable to untwist. ${ }^{6-8}$

Diagnosing a case of omental torsion could be very difficult as the primary symptom associated with omental torsion is un remitting abdominal pain of acute onset localized in the right iliac fossa similar to acute appendicitis. ${ }^{9,10}$ Pain is usually sudden in onset which does not radiate but is associated with nausea, vomiting and low-grade fever; the bowel moments are usually normal. ${ }^{11,12}$ Depending on age and features of pain, list of differential diagnosis is over a long spectrum and includes acute cholecysystitis, cecal diverticulitis, perforated duodenal ulcer, abdominal wall hematoma; ${ }^{12}$ while in women of reproductive age it includes salpingitis, ovarian cyst torsion, ectopic pregnancy; and in children's, meckel diverticulum and mesenteric adenitis are also included. ${ }^{13}$ Torsion of accessory spleen is another diagnostic possibility due to the fact that accessory spleen, when it exists, usually resides inside the omentum. ${ }^{7}$

Laboratory results in torsion of the omentum are usually normal or show slight increase in inflammatory markers but are non-diagnostic. . $^{2,14}$ The majority of cases of omental torsion and infraction reported in the literature were segmental involving the right side of the omentum; left sided omental torsion is unusual but has been described. ${ }^{3}$ Ultrasound (US) abdomen is usually normal in these patients but sometime it may reveal mass or hypoechoic zones, and is mandatory to rule out other acute abdominal causes. CT is more helpful in diagnosing this condition, and a typical CT finding will include focal thickening of fat density showing streaks in whirling pattern and presence of serosanguinous fluid as minimal ascites. This is sometime associated with adjacent bowel wall thickening. Small bowel volvulus shares same CT findings but clinically patient would have signs and symptoms suggestive of intestinal obstruction and can easily be differentiated from omental torsion. ${ }^{9,10}$

We present this unique case of omental torsion that came in emergency ward as pain right iliac fossa and was diagnosed as acute appendicitis based on clinical and laboratory findings. Our patient had a BMl of $36.6 \mathrm{~kg} / \mathrm{m}^{2}$ which is one of the main predisposing factors in primary omental torsion. CT abdomen or laparoscopy might had help in early diagnosis and management of this condition but are unfortunately not present in emergency ward of the most of tertiary care teaching hospitals of this part of world due to economic reasons and was not performed. US findings were inconclusive in this patient. Diagnosis of omental torsion was made during exploratory laparotomy when we come across with gangrenous omental during appendectomy.

Treatment of omental torsion in literature is reported as both conservative and surgical. $., 8,15,16,17$ Conservative treatmentalthough is only reported in a few cases of acute abdomen without obstruction and should be reserved for unambiguous radiological diagnosis. ${ }^{16-17}$ Surgical procedure is the treatment of choice in order to prevent complications. This procedure can be performed either an open laparotomy or laparoscopically; and involves the resection of the affected part of omentum. ${ }^{18,19}$ Exploratory laparotomy serves as diagnostic and therapeutic procedure as the torsion is diagnosed during exploratory laparotomy performed for acute abdomen therefore surgical treatment is still procedure 
of choice.12,14 It further gives advantage over conservative approach by preventing possible complications such as sepsis, intraabdominal abscess or adhesion formation. ${ }^{14,16,17,19}$

Minimally Invasive approaches like diagnostic and therapeutic laparoscopy however is preferred over exploratory laparotomy, as it result in faster recovery, shorter hospital stay, less scarring, minimally incision and earliest discharge as day case patient with an excellent outcome.

\section{CONCLUSION}

Omental torsion is an extremely rare condition, and surgeons should have high index of clinical suspicion to diagnose it in elderly obese males. CT imaging should be requested in ambiguous clinical findings, and laparoscopy should be preferred to manage right iliac fossa pain.

Copyright@ 08 July, 2021.

\section{REFERENCES}

1. Lindley SI, Peyser PM. Idiopathic omental infarction: One for conservative or surgical management? J Surg Case Rep. 2018 Mar 26; 2018(3):rjx095. doi: 10.1093/ jscr/rjx095. PMID: 29599961; PMCID: PMC5868192.

2. $\mathrm{Ng} \mathrm{B}$, Yasser A. International Journal of Surgical Case Reports. 2019:1. https://doi.org/10.31487/j. IJSCR.2019.02.03.

3. Corvino, A., Campanino, M.R., De Rosa, N. et al. Leftsided omental infarction without torsion: Report of a case with radiologic-pathologic correlation. Egypt J Radiol Nucl Med 51, 117 (2020). https://doi.org/10.1186/ s43055-020-00235-w.

4. Andreuccetti J, Ceribelli C, Manto O, Chiaretti M, Negro P, Tuscano D. Primary omental torsion (POT): A review of literature and case report. World $\mathrm{J}$ Emerg Surg. 2011 Jan 26; 6:6. doi: 10.1186/1749-7922-6-6. PMID: 21269497; PMCID: PMC3038905.

5. Eitel GG: Rare omental torsion. NY Med Rec. 1899; 55: 715-716

6. Chinaka C, Mansoor S, Salaheidin M. Torsion of the omentum: A Rare Cause of Acute Abdomen in a 14-Year-Old Boy. Case Rep Surg. 2018 Jan 31; 2018:7257460. doi: 10.1155/2018/7257460. PMID: 29666745; PMCID: PMC5831312.
7. Occhionorelli S, Zese M, Cappellari L, Stano R, Vasquez G. Acute abdomen due to primary omental torsion and infarction. Case Rep Surg. 2014; 2014:208382. doi: 10.1155/2014/208382. Epub 2014 Nov 6. PMID: 25431726; PMCID: PMC4241260.

8. Mendoza Moreno F, Díez Gago Mdel R, Córdova García DM, Pedraza Muñoz A, Díez Alonso M, Noguerales Fraguas F, Granell Vicent FJ. Primary omental torsion as presentation of acute abdomen. Case report. Rev Esp Enferm Dig. 2016 Feb; 108(2):105-6. doi: 10.17235/ reed.2015.3850/2015. PMID: 26838496.

9. Nubi A, McBride W, Stringel G. Primary omental infarct: Conservative vs operative management in the era of ultrasound, computerized tomography, and laparoscopy. J Pediatr Surg. 2009 May; 44(5):953-6. doi: 10.1016/j.jpedsurg.2009.01.032. PMID: 19433177.

10. Abdennasser el K, Driss B, Abdellatif D, Mehci A, Souad $C$, Mohamed B. Omental torsion and infarction: CT appearance. Intern Med. 2008; 47(1):73-4. doi: 10.2169/internalmedicine.47.0538. Epub 2008 Jan 1. PMID: 18176011

11. Alexiou K, Ioannidis A, Drikos I, Sikalias N, Economou N. Torsion of the greater omentum: Two case reports. J Med Case Rep. 2015 Jul 11; 9:160. doi: 10.1186/s13256015-0641-5. PMID: 26163136; PMCID: PMC4507315.

12. Yu JS, Lee WS, Kim YH. Primary torsion of lesser omentum presented with acute abdomen and successfully managed with laparoscopic surgery. Chin Med J (Engl). 2016 Jul 5; 129(13):1625-6. doi: 10.4103/0366-6999.184469. PMID: 27364803; PMCID: PMC4931273.

13. Tsironis A., Zikos N., Bali C., Pappas-Gogos G., Koulas S., Katsamakis N. Primary torsion of the greater omentum: Report of two cases and review of the literature. The Internet Journal of Surgery. 2008;17:239246

14. Dhooghe V, Reynders D, Cools P. Torsion of a bifid omentum as a rare cause of acute abdomen: $A$ case report. J Med Case Rep. 2016 Oct 19; 10(1):289. doi: 10.1186/s13256-016-1070-9. PMID: 27756378; PMCID: PMC5070124.

15. Gaba S, Gaba N, Gupta M. Omental infarction imitating acute appendicitis. Cureus. 2020 Jun 19; 12(6):e8704. doi: 10.7759/cureus.8704. PMID: 32699700; PMCID: PMC7372225.

16. Coppin T, Lipsky D. Twisting and infarction of the entire greater omentum managed by laparoscopy: A report of two cases. Acta Chir Belg. 2006 Mar-Apr; 106(2):215-7. doi: 10.1080/00015458.2006.11679874. PMID: 16761481. 
17. Coco D, Leanza S, Mattioli G. A 26-Year-Old man with acute abdomen due to omental torsion: $A$ rare case report. Maedica (Bucur). 2021 Mar; 16(1):125-129. doi: 10.26574/maedica.2020.16.1.125. PMID: 34221167; PMCID: PMC8224712.

18. Johri V., Dhaduk V., Mushtaque N., Jain N., Reddy P. K. Role of laparoscopy as diagnostic and therapeutic tool in management of omental torsion. Sri Lanka Journal of Surgery. 2018; 36(1):p. 39. doi: 10.4038/sljs. v36i1.8482.
19. Mihetiu A, Sandu A, Bratu D, Mihetiu C. Laparoscopic management of primary omental torsion. Case Rep Surg. 2021 Feb 24; 2021:5536178. doi: 10.1155/2021/5536178. PMID: 33708451; PMCID: PMC7932802.

\begin{tabular}{|c|c|c|c|}
\hline \multicolumn{4}{|c|}{ AUTHORSHIP AND CONTRIBUTION DECLARATION } \\
\hline No. & Author(s) Full Name & Contribution to the paper & Author(s) Signature \\
\hline 1 & Gul e Lala & $\begin{array}{l}\text { Data provision, analysis, } \\
\text { manuscript writing, admin } \\
\text { support. } \\
\text { Provision of data, Manuscript } \\
\text { writing. }\end{array}$ & \\
\hline 3 & Abdullah Khan & Manuscript writing. & \\
\hline
\end{tabular}

